\title{
Reported Stroke Symptoms and their Associated Risk Factors in the Kingdom of Saudi Arabia, 2013
}

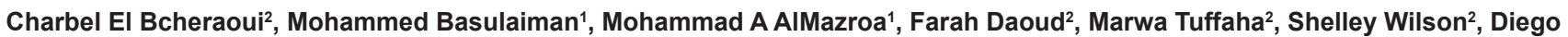

Gonzalez-Medina ${ }^{2}$, Ziad A Memish ${ }^{1}$, Mohammed Al Saeedi' ${ }^{2}$, and Ali H Mokdad*2

${ }^{1}$ Ministry of Health of the Kingdom of Saudi Arabia, Assadah, Al Murabba Riyadh 12613, Saudi Arabia

${ }^{2}$ Institute for Health Metrics and Evaluation, University of Washington, 2301 Fifth Ave., Suite 600, Seattle, WA 98121, USA

\begin{abstract}
Background: Stroke is the second leading cause of death globally, and in the Kingdom of Saudi Arabia, with hypertension being the predominant risk factor. At-risk individuals experience stroke symptoms but remain undiagnosed. However, no data exist on stroke symptoms and their associated factors in KSA. We assessed self-reported stroke symptoms and their association with pre-diabetes, diabetes, hypercholesterolemia, hypertension, and health seeking behaviors.
\end{abstract}

Methods: We conducted a nationally representative multistage survey of individuals aged 15 years or older on socio-demographic characteristics; tobacco consumption, diet, physical activity, health care utilization, different healthrelated behaviors, and self-reported chronic conditions. We used a backward elimination multivariate logistic regression model to measure associations between symptoms of stroke and risk factors.

Results: Between April and June 2013, a total of 12,000 households were contacted and a total of 10,735 participants completed the survey (response rate of $89.4 \%)$. Overall, 579 (4.8\% age-adjusted) respondents reported experiencing at least one symptom of stroke, while 55 ( $0.4 \%$ age-adjusted) reported being previously diagnosed with a stroke. The likelihood of reporting symptoms of stroke was associated with sex, older age, high levels of physical activity, and a history of diagnoses of any of the following conditions: pre-diabetes, diabetes, hypercholesterolemia, and hypertension. Our study showed that a high percentage of Saudis reporting stroke symptoms have undiagnosed or uncontrolled blood pressure. Moreover, $61 \% \%$ of those reporting stroke symptoms have never been to a doctor.

Conclusions: Our study showed that a high percentage of individuals with suspected stroke have not sought medical care. Moreover, a large proportion of those with reported symptoms have uncontrolled conditions. To reduce the burden on stroke in KSA, prevention and control strategies should be accelerated with a focus on use of free preventive care services.

Keywords: Stroke, Symptoms; Kingdom of Saudi Arabia; Hypertension

Abbreviations: KSA: Kingdom of Saudi Arabia; BMI: Body Mass Index; SHIS: Saudi Health Information Survey; REF: Reference group; SE: Standard error, OR: Adjusted odds ratio; CI: Confidence Interval; AOR: Adjusted Odds Ratio.

\section{Introduction}

Stroke is the second leading cause of death globally, and in the Kingdom of Saudi Arabia (KSA) [1]. The 2010 Global Burden of Disease estimated that 5.3 million deaths were due to stoke worldwide with 75\% occurring in low and middle income countries [2]. In KSA, stroke account for 10,000 deaths, 191,000 disability-adjusted life years, and 185,000 years of life lost [3].

Stroke symptoms vary from headaches to numbness, confusion, vision trouble, trouble walking, aphasia and even death [4]. Hypertension is the major risk factor for stroke, and its control is the most effective strategy to prevent stroke $[5,6]$.Only a few studies have reported on stroke in KSA since the early nineties. A stroke registry was operated in the Eastern Province between 1989 and 1993 [7]. The registry data showed a $0.1 \%$ incidence rate per year of first-ever stroke among Saudi nationals with ischemic strokes accounting for $69 \%$ of these cases, and a first-month fatality rate of $15 \%$. Awada and Al Rajeh reported 1,280 admissions for stroke from two major Saudi hospitals between 1982 and 1995 [8]. However, no denominator was provided to estimate the relative incidence. On the other hand, Al Rajeh et al. reported an annual incidence rate of $0.4 \%$ between 1982 and 1992 among the KSA National Guard [9] with $12 \%$ mortality within the first month. Smoking and hypertension were the predominant risk factors in the three studies.

In previous studies, hypertension prevalence ranged from $26.1 \%$ among individuals $30-70$ years old in $1995-2000$ to $25.5 \%$ among individuals 15 - 64 years old in 2005 [10-12]. We have recently reported a prevalence of $15.2 \%$ hypertension among Saudi adults aged 15 or older for 2013 [13].Among Saudis suffering from hypertension, $57.8 \%$ are undiagnosed, $20.2 \%$ are treated uncontrolled, $16.6 \%$ are treated controlled, and 5.4\%,are untreated.

Often, persons with stroke-associated risk factors experience stroke symptoms but remain undiagnosed by a healthcare professional [14]. However, early detection of these symptoms is crucial to prevent their progression or re-occurrence.

*Corresponding author: Ali $\mathrm{H}$ Mokdad, Director, Middle Eastern Initiatives, Professor, Global Health, Institute for Health Metrics and Evaluation, University of Washington, 23015 th Avenue, Suite 600, Seattle, WA 98121 Tel:1-206-897-2849; Fax: 1-206-897-2899; E-mail: mokdaa@uw.edu

Received July 28, 2014; Accepted September 27, 2014; Published October 01 2014

Citation: Bcheraoui TCEI, Basulaiman M, AIMazroa MA, Daoud F, Tuffaha M, et al. (2014) Reported Stroke Symptoms and their Associated Risk Factors in the Kingdom of Saudi Arabia, 2013. J Hypertens 3: 177. doi:10.4172/21671095.1000177

Copyright: () 2014 Bcheraoui TCEI, et al. This is an open-access article distributed under the terms of the Creative Commons Attribution License, which permits unrestricted use, distribution, and reproduction in any medium, provided the original author and source are credited. 
No data exist on stroke symptoms and their associated factors in KSA. We assessed self-reported symptoms of stroke and their association with pre-diabetes, diabetes, hypercholesterolemia and hypertension. We further examined the healthcare use patterns to identify potential missed opportunities in identifying at-risk groups, and to better develop and implement stroke preventive measures.

\section{Materials and Methods}

The Saudi Health Information Survey (SHIS) is a national multistage survey of individuals aged 15 years or older. Households of Saudi citizens were randomly selected from a national sampling frame maintained and updated by the Census Bureau. The Ministry of Health divides KSA into 13 health regions, each with its own health department. We divided each region into sub-regions and blocks used by the KSA Department of Statistics. All regions were included, and a probability proportional to size was used to randomly select subregions and blocks. Households were randomly selected from each block. A roster of household members was collected and an adult aged 15 or older was randomly selected to be surveyed. If the randomly selected adult was not present, our surveyors made an appointment to return, and a total of three visits were made before the household was classified as a non-response. Weight, height, and blood pressure of the randomly selected adult were measured at the household by a trained professional.

The surveyincluded questions on socio-demographic characteristics, tobacco consumption, diet, physical activity, health care utilization, health-related behaviors, and self-reported chronic conditions. These conditions were hypertension, diabetes, hypercholesterolemia, stroke, cardiac arrest, myocardial infarction, congestive heart failure, chronic obstructive pulmonary disease, atrial fibrillation, renal failure, asthma, and cancer.

We used measured weight and height to calculate BMI as weight $(\mathrm{kg}) /$ height $\left(\mathrm{m}^{2}\right)$. Participants were classified into four groups: 1) Underweight for a BMI less than 18.5 ; 2) Normal weight for a BMI within 18.5 - 24.9; 3) overweight for a BMI within 25.0-29.9; or obese if their BMI was greater than or equal to 30 [15]. Respondents were considered to be current smokers if they reported currently smoking. We used the International Physical Activity questionnaire [16] to classify respondents into four groups of physical activity: 1) vigorous physical activity, 2) moderate physical activity, 3) insufficient physical activity, and 4) none.

To assess diagnosed blood pressure, pre-diabetes, diabetes, and hypercholesterolemia status, respondents were asked four separate questions: "Have you ever been told by a doctor, nurse, or other health professional that you had: 1) hypertension, otherwise known as high blood pressure; 2) pre-diabetes mellitus, otherwise known as pre-diabetes, borderline diabetes, impaired fasting glucose, impaired glucose tolerance, or impaired sugar tolerance; 3) diabetes mellitus, otherwise known as diabetes, sugar diabetes, high blood glucose, or high blood sugar; 4) hypercholesterolemia, otherwise known as high or abnormal blood cholesterol?" Women diagnosed with diabetes or hypertension during pregnancy was not counted as having these conditions. Those who reported diagnosis of any of these conditions were asked if they were currently receiving any treatment for their condition. Similarly, the same question format was used to determine previous diagnosis of stroke.

To assess symptoms of stroke, respondents were asked three separate questions: "1) Have you ever had sudden painless weakness on one side of your body that lasted for at least 24 hours? 2) Have you ever had sudden numbness or a dead feeling on one side of your body? 3) Have you ever suddenly lost the ability to understand what people were saying or lost the ability to express yourself verbally or in writing for at least 24 hours?" Those who reported at least one of these symptoms were considered symptomatic for stroke.

A total of three blood measurements were taken with the participant resting and at five-minute intervals. We followed the National Health and Nutrition Examination Survey (NHANES) for editing and determining blood pressure levels [17]. If only one reading was available for systolic blood pressure, this reading was the one used. If two readings were available, then only the second reading was taken into account. If three readings were available, then the average of the last two readings was considered as the systolic blood pressure. The same method was used for calculating diastolic blood pressure. Respondents were considered to have elevated blood pressure if they met either of the following criteria: 1) measured diastolic or systolic blood pressure exceeding 90 or $140 \mathrm{mmHg}$, respectively or 2) measured diastolic or systolic blood pressure not exceeding the appropriate threshold but the respondent reported taking medications for blood pressure.

We compared socio-demographic characteristics of individuals who exhibited symptoms of stroke to those who were diagnosed with stroke and those who reported no diagnosis nor symptoms of stroke. We used a backward elimination multivariate logistic regression model to measure association between symptoms of stroke and associated factors. All factors were included in the model. Then variables were eliminated based on a Wald chi-square test for analysis of effect. Variables were removed one by one based on the significance level of their effect on the model, starting with the variable with the highest $p>0.5$, until all variables retained had a $p \leq 0.5$ in the analysis of effect. The logistic regression excluded cases with missing data. We used another backward elimination multivariate logistic regression model to measure association between hypertension and symptoms of stroke. Hypertension status and management were compared between individuals who experienced one symptom of stroke or more. Time since last routine medical exam was compared between individuals who experienced one symptom of stroke or more, then restricted to those who are undiagnosed hypertensive, and then those who had no diagnosis of any of the chronic diseases cited above at all. We used SAS 9.2 (SAS Institute Inc., Cary, NC, USA) for analyses and to account for the complex sampling design.

\section{Results}

Between April and June 2013, a total of 12,000 households were contacted and a total of 10,735 participants completed the survey (response rate of $89.4 \%$ ). Overall, 579 (4.8\% age-adjusted) respondents reported experiencing at least one symptom of stroke, while $55(0.4 \%$ age-adjusted) reported being previously diagnosed with a stroke. Socio-demographic characteristics of SHIS respondents by stroke-free, diagnosed, and reported stroke symptoms are presented in Table 1, and Figure 1 .

The likelihood of reporting stroke symptoms was associated with the female sex, older age, high levels of physical activity, and a history of diagnoses of any of the following conditions: pre-diabetes, diabetes, hypercholesterolemia, and hypertension (Table 2). About 15\% of Saudis are hypertensive. When adjusted for age, sex, marital status, and education, those who reported two or three symptoms of stroke were more likely to be hypertensive compared to those who did not report any symptoms of stroke $(\mathrm{AOR}=3.0 ; 95 \% \mathrm{CI}$ : $1.6-5.7)$. This association 
Citation: Bcheraoui TCEI, Basulaiman M, AIMazroa MA, Daoud F, Tuffaha M, et al. (2014) Reported Stroke Symptoms and their Associated Risk Factors in the Kingdom of Saudi Arabia, 2013. J Hypertens 3: 177. doi:10.4172/2167-1095.1000177

Page 3 of 6

\begin{tabular}{|c|c|c|c|c|c|c|c|c|c|}
\hline \multirow[b]{2}{*}{ Socio-demographic characteristics } & \multicolumn{3}{|c|}{ No symptoms of stroke } & \multicolumn{3}{|c|}{ Previously diagnosed with stroke } & \multicolumn{3}{|c|}{ Reported stroke symptoms } \\
\hline & $\mathbf{N}$ & Weighted \% & SE & $\mathbf{N}$ & Weighted \% & SE & $\mathbf{N}$ & Weighted \% & SE \\
\hline \multicolumn{10}{|l|}{ Sex } \\
\hline Males & 4982 & 95.5 & 0.4 & 35 & 0.4 & 0.1 & 221 & 4.1 & 0.4 \\
\hline Female & 5118 & 95.0 & 0.4 & 20 & 0.3 & 0.1 & 321 & 4.7 & 0.4 \\
\hline \multicolumn{10}{|l|}{ Age } \\
\hline $15-24$ & 2292 & 96.7 & 0.4 & 4 & 0.1 & 0.03 & 83 & 3.2 & 0.4 \\
\hline $25-34$ & 2660 & 96.5 & 0.5 & 6 & 0.2 & 0.1 & 86 & 3.3 & 0.5 \\
\hline $35-44$ & 2236 & 95.3 & 0.6 & 8 & 0.3 & 0.2 & 89 & 4.4 & 0.6 \\
\hline $45-54$ & 1397 & 92.8 & 0.9 & 4 & 0.1 & 0.1 & 108 & 7.1 & 0.9 \\
\hline $55-64$ & 786 & 93.4 & 1.0 & 9 & 0.8 & 0.3 & 65 & 5.8 & 0.9 \\
\hline $65+$ & 729 & 84.7 & 1.8 & 24 & 3.5 & 1.1 & 111 & 11.8 & 1.5 \\
\hline \multicolumn{10}{|l|}{ Marital status } \\
\hline Currently married & 6586 & 94.8 & 0.3 & 34 & 0.4 & 0.1 & 335 & 4.8 & 0.3 \\
\hline Never married & 2712 & 96.5 & 0.4 & 6 & 0.1 & 0.03 & 104 & 3.4 & 0.4 \\
\hline Separated, divorced, or widowed & 775 & 89.2 & 1.4 & 15 & 2.3 & 0.9 & 100 & 8.5 & 1.2 \\
\hline \multicolumn{10}{|l|}{ Education } \\
\hline Primary school or less & 2978 & 93.3 & 0.6 & 39 & 0.9 & 0.2 & 248 & 5.8 & 0.5 \\
\hline Elementary or high school completed & 4665 & 96.3 & 0.3 & 13 & 0.2 & 0.1 & 183 & 3.5 & 0.3 \\
\hline College degree or higher education & 2442 & 95.3 & 0.6 & 3 & 0.1 & 0.1 & 109 & 4.6 & 0.6 \\
\hline
\end{tabular}

Note: those who reported a history of stroke diagnosis are excluded from those who reported stroke symptoms SE = Standard error

Table 1: socio-demographic characteristics by symptoms and diagnosis of stroke, Kingdom of Saudi Arabia, 2013.

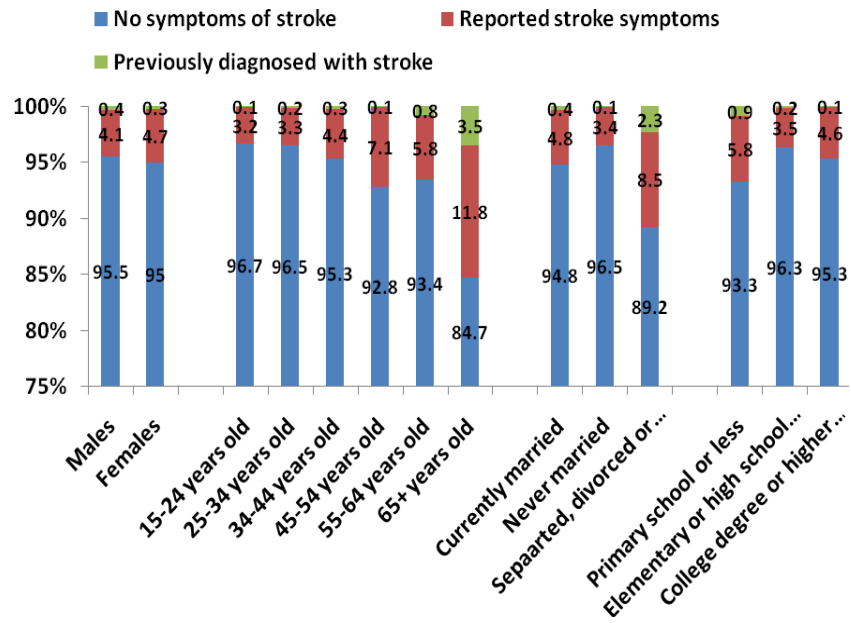

Figure 1: Distribution of symptoms and diagnosis of stroke by sociodemographic characteristics, Kingdom of Saudi Arabia, 2013.

was not true for those who experienced only one symptom of stroke $(\mathrm{AOR}=1.4 ; 95 \% \mathrm{CI}: 0.9-2.1)$.

Among individuals who reported no symptoms of stroke, $15.0 \%$ were hypertensive. With the increase of number of reported stroke symptoms, the prevalence of undiagnosed, diagnosed and treated, treated and controlled, and treated and uncontrolled hypertension also increased (Table 3).

On average, time since last routine medical exam was shorter among individuals who reported experiencing stroke symptoms compared to those who did not (Table 4). The same patterns were observed when data was restricted to individuals who were hypertensive but undiagnosed, and also to those who have no diagnosis history of any of the four chronic conditions: hypertension, hypercholesterolemia, prediabetes, and diabetes (data not presented).

When we examined the percentage of reported stroke symptoms among those who were previously diagnosed with stroke, $63.7 \%$ reported these symptoms compared to $4.3 \%$ among those not previously diagnosed with stroke.

\section{Discussion}

Our national study was the first to examine the symptoms of strokes and their determinants in KSA. We found a large number of selfreported symptoms that should have triggered a more comprehensive medical examination. However, about $61.0 \%$ (age adjusted) or an estimated 364,846 of Saudis reporting symptoms have never seen a medical doctor. Our findings call for awareness campaigns for signs of stroke in KSA and for proper management of these cases including regular checkups to ensure control of risk factors and reduce the burden of stroke in the Kingdom.

Our findings that individuals who reported symptoms of stroke and have been diagnosed with hypertension are not controlling their blood pressure is troublesome. Indeed, about $8.2 \%$ of those reporting symptoms had uncontrolled blood pressure. Hence, an estimated 47,712 Saudis with symptoms of stroke know about their blood pressure condition and are on medication but not controlling a major risk for stroke. These individuals need adequate follow-up care to ensure their blood pressure is controlled.

Our study showed that $67.7 \%$ (an estimated 392,513) of those reporting symptoms for stroke had undiagnosed hypertension, compared to only $8.6 \%$ of those who have no history of stroke diagnosis or stroke symptoms. The association with hypertension is very likely confirming that these stroke symptoms are real. Furthermore, our study showed that only 13 of those who reported stroke symptoms are taking an anticoagulant (11 on aspirin and two on others). Individuals with such symptoms should be closely monitored for blood pressure and other stroke risk factors. Indeed, there is an urgent need to inform Saudis of the importance of preventive care and identifying danger signs. Moreover, the fact that Saudis have free access to health care indicates that cost is not an issue here. 
Citation: Bcheraoui TCEI, Basulaiman M, AIMazroa MA, Daoud F, Tuffaha M, et al. (2014) Reported Stroke Symptoms and their Associated Risk Factors in the Kingdom of Saudi Arabia, 2013. J Hypertens 3: 177. doi:10.4172/2167-1095.1000177

Page 4 of 6

\begin{tabular}{|c|c|c|c|c|c|c|c|c|}
\hline \multirow[b]{2}{*}{ Socio-demographic characteristics } & \multicolumn{3}{|c|}{ No symptoms of stroke } & \multicolumn{3}{|c|}{ Reported stroke symptoms } & \multicolumn{2}{|c|}{ Logistic regression } \\
\hline & $\mathbf{N}$ & Weighted \% & SE & $\mathbf{N}$ & Weighted \% & SE & AOR & $95 \% \mathrm{Cl}$ \\
\hline \multicolumn{9}{|l|}{ Sex } \\
\hline Males & 4990 & 95.7 & 0.4 & 248 & 4.3 & 0.4 & REF & \\
\hline Female & 5128 & 95.1 & 0.4 & 331 & 4.9 & 0.4 & 1.6 & $1.13-2.17$ \\
\hline Age $^{a}$ & & & & & & & 1.4 & $1.15-1.67$ \\
\hline $15-24$ & 2239 & 96.8 & 0.4 & 86 & 3.2 & 0.4 & & \\
\hline $25-34$ & 2662 & 96.6 & 0.5 & 90 & 3.4 & 0.5 & & \\
\hline $35-44$ & 2241 & 95.6 & 0.6 & 92 & 4.4 & 0.6 & & \\
\hline $45-54$ & 1399 & 92.9 & 0.9 & 110 & 7.1 & 0.9 & & \\
\hline $55-64$ & 788 & 93.5 & 1.0 & 72 & 6.5 & 1.0 & & \\
\hline $65+$ & 735 & 85.5 & 1.8 & 129 & 14.5 & 1.8 & & \\
\hline \multicolumn{9}{|l|}{ Marital status } \\
\hline Currently married & 6598 & 95. & 0.3 & 357 & 5.0 & 0.3 & REF & \\
\hline Never married & 2715 & 96.5 & 0.4 & 107 & 3.5 & 0.4 & 1.4 & $0.98-2.07$ \\
\hline Separated, divorced, or widowed & 778 & 89.8 & 1.4 & 112 & 10.2 & 1.4 & 1.4 & $0.94-2.08$ \\
\hline \multicolumn{9}{|l|}{ Education } \\
\hline Primary school or less & 2998 & 93.5 & 0.6 & 277 & 6.5 & 0.6 & REF & \\
\hline Elementary or high school completed & 4670 & 96.5 & 0.3 & 191 & 3.5 & 0.3 & 1.1 & $0.78-1.63$ \\
\hline College degree or higher education & 2445 & 95.4 & 0.6 & 109 & 4.6 & 0.6 & 1.3 & $0.88-1.97$ \\
\hline \multicolumn{9}{|l|}{ Smoking status } \\
\hline Never smoked & 8384 & 95.5 & 0.3 & 478 & 4.5 & 0.3 & REF & \\
\hline Ex-smoker & 419 & 922 & 1.6 & 41 & 7.8 & 15 & 1.3 & $0.73-2.22$ \\
\hline Current smoker & 1292 & 95.8 & 0.7 & 60 & 4.2 & 0.7 & 0.8 & $0.54-1.33$ \\
\hline \multicolumn{9}{|l|}{ Levels of physical activity } \\
\hline None & 4003 & 95.8 & 0.4 & 237 & 4.2 & 0.4 & REF & \\
\hline Low & 2455 & 95.4 & 0.5 & 117 & 4.6 & 0.5 & 1.3 & $0.89-1.78$ \\
\hline Moderate & 1276 & 94.8 & 0.9 & 74 & 5.2 & 0.9 & 1.4 & $0.87-2.19$ \\
\hline High & 2384 & 95.2 & 0.5 & 151 & 4.8 & 0.5 & 1.9 & $1.31-2.67$ \\
\hline \multicolumn{9}{|l|}{ Obesity } \\
\hline Not obese & 6546 & 95.9 & 0.3 & 329 & 4.1 & 0.3 & & \\
\hline Obese & 3221 & 94.3 & 0.5 & 226 & 5.7 & 0.5 & & \\
\hline \multicolumn{9}{|l|}{ History of diagnosis with pre-diabetes } \\
\hline No & 9758 & 95.8 & 0.3 & 508 & 4.2 & 0.3 & REF & \\
\hline yes & 162 & 79.6 & 4.1 & 39 & 20.4 & 4.1 & 2.9 & $1.55-5.35$ \\
\hline \multicolumn{9}{|l|}{ History of diagnosis with diabetes } \\
\hline No & 8964 & 96.2 & 0.3 & 400 & 3.8 & 0.3 & REF & \\
\hline Yes & 1072 & 87.5 & 1.3 & 167 & 12.5 & 1.3 & 1.8 & $1.16-2.66$ \\
\hline \multicolumn{9}{|c|}{ History of diagnosis with hypercholesterolemia } \\
\hline No & 9300 & 96.3 & 0.3 & 404 & 3.7 & 0.3 & REF & \\
\hline Yes & 639 & 86.0 & 1.6 & 119 & 14.0 & 1.6 & 2.0 & $1.33-3.03$ \\
\hline \multicolumn{9}{|c|}{ History of diagnosis with hypertension } \\
\hline No & 9185 & 96.1 & 0.3 & 415 & 3.9 & 0.3 & REF & \\
\hline Yes & 864 & 86.7 & 1.4 & 156 & 13.3 & 1.4 & 1.55 & $1.00-2.40$ \\
\hline
\end{tabular}

Note: those who reported a history of stroke diagnosis are excluded from those who reported stroke symptoms

$\mathrm{REF}=$ Reference group; $\mathrm{SE}=$ Standard error; $\mathrm{OR}=$ Adjusted odds ratio; $\mathrm{Cl}=$ Confidence interval; $\mathrm{AOR}=$ Adjusted odds ratio.

aAge was used as a continuous variable in the logistic regression models. Hence, the AOR for age indicates an increase of one year of age

Table 2: Multivariate logistic regression for socio-demographic characteristics, risk factors, and symptoms of stroke, males and females aged 15 years or older, Kingdom of Saudi Arabia, 2013.

\section{Limitations}

Our study has some limitations. First, our self-reported stroke symptoms are not confirmative of the presence of stroke. However, they are a good indication to seek medical care. Second, many of our variables are self-reported and maybe subject to recall errors. Third, our reported symptoms are not for a specific time period since our questions are whether the individuals had ever experienced such symptoms. Finally, our study is cross sectional and hence we cannot determine causation. On the other hand, our study is based on a large sample size and we have measured blood pressure, weight, and height using standard methodology enabling us to examine the association of these risk factors with stroke symptoms.
There is no active stroke registry currently in KSA. Previous attempts have not been maintained and their data has not been recorded properly. The Saudi Ministry of Health needs an active registry to monitor the incidence of stroke and promote studies on its epidemiology in KSA. Moreover, Saudi citizens have a unique identification number that could easily be used to link data throughout their interaction with medical systems. This would make the monitoring and studying of causes and patterns of stroke as well as other health conditions easier. Also, a link to mortality data and causes of death could enable examination of previous risks and their impact on mortality. 
Citation: Bcheraoui TCEI, Basulaiman M, AIMazroa MA, Daoud F, Tuffaha M, et al. (2014) Reported Stroke Symptoms and their Associated Risk Factors in the Kingdom of Saudi Arabia, 2013. J Hypertens 3: 177. doi:10.4172/2167-1095.1000177

Page 5 of 6

\begin{tabular}{|c|c|c|c|c|c|c|c|c|c|}
\hline \multirow[b]{2}{*}{ Hypertension status } & \multicolumn{3}{|c|}{ No symptoms } & \multicolumn{3}{|c|}{1 symptom } & \multicolumn{3}{|c|}{2 or 3 symptoms } \\
\hline & $\mathbf{N}$ & Weighted \% & SE & $\mathbf{N}$ & Weighted \% & SE & $\mathbf{N}$ & Weighted \% & SE \\
\hline Healthy & 8048 & 85.0 & 0.5 & 239 & 74.4 & 3.1 & 96 & 56.3 & 5.6 \\
\hline Hypertensive undiagnosed & 1028 & 8.6 & 0.4 & 41 & 11.3 & 2.3 & 18 & 13.4 & 4.0 \\
\hline Hypertensive untreated & 160 & 1.4 & 0.1 & 14 & 3.9 & 1.5 & 7 & 3.7 & 1.6 \\
\hline Treated controlled & 293 & 2.2 & 0.2 & 24 & 5.6 & 1.5 & 29 & 11.0 & 2.5 \\
\hline Treated uncontrolled & 390 & 2.8 & 0.2 & 29 & 4.9 & 1.3 & 29 & 15.6 & 3.8 \\
\hline
\end{tabular}

Note: those who reported a history of stroke diagnosis are excluded from those who reported stroke symptoms

SE = Standard error

Table 3: Distribution of stroke symptoms by status of hypertension, and hypertension management, males and females aged 15 years or older, Kingdom of Saudi Arabia, 2013.

\begin{tabular}{|c|c|c|c|c|c|c|c|c|c|}
\hline \multirow[b]{2}{*}{ Last medical checkup } & \multicolumn{3}{|c|}{ No symptoms } & \multicolumn{3}{|c|}{1 symptom } & \multicolumn{3}{|c|}{2 or 3 symptoms } \\
\hline & $\mathbf{N}$ & Weighted \% & SE & $\mathbf{N}$ & Weighted \% & SE & $\mathbf{N}$ & Weighted \% & SE \\
\hline Last year & 1651 & 14.2 & 0.5 & 93 & 26.5 & 3.2 & 60 & 26.5 & 4.4 \\
\hline $1-3$ years ago & 924 & 8.5 & 0.4 & 43 & 10.5 & 2.2 & 18 & 12.5 & 4.1 \\
\hline $4+$ years ago & 160 & 1.4 & 0.2 & 5 & 1.1 & 0.6 & 2 & 0.8 & 0.6 \\
\hline Never & 7365 & 75.9 & 0.6 & 213 & 61.9 & 3.5 & 108 & 60.2 & 5.3 \\
\hline
\end{tabular}

Note: those who reported a history of stroke diagnosis are excluded from those who reported stroke symptoms

SE $=$ Standard error

Table 4: Distribution of stroke symptoms by time since last routine medical checkup, males and females aged 15 years or older, Kingdom of Saudi Arabia, 2013.

In the United States, $3 \%$ of adults aged 18 years or older have been told by a doctor they have had a stroke [18] compared to $0.4 \%$ among Saudis aged 18 years or older. However, in the United States, prevalence of hypertension is also higher than in KSA as $24 \%$ of adults aged 18 years or older have been told by a doctor they have hypertension [18], and $33.5 \%$ of the U.S. population aged 20 years or older has diagnosed and treated, or measured hypertension [19].

In our study women have reported more symptoms of stroke than men. Olives et al. reported that US women are less likely to control their blood pressure than men [20]. However, this is not the case among Saudis as we previously reported that Saudi women are doing a better job controlling their blood pressure than men: $20.5 \%$ vs $13.9 \%$ of hypertensive Saudi women and men on treatment for hypertension have their blood pressure controlled.

The Saudi population is young. The 2010 census showed that $81 \%$ of the population is under the age of 40 . As the population ages, the burden of chronic diseases and their risk factors will rise. Hence the role of prevention has to be at the forefront of the health authority activities. KSA still faces a major burden of infectious diseases as it hosts pilgrims from all over the world in close proximities [21]. However, the burden of non-communicable diseases is rising and deserves a shift in the public health practice with a heavy focus on prevention.

Our study showed that a high percentage of Saudis reporting stroke symptoms have undiagnosed or uncontrolled blood pressure. Moreover, it showed that a large percentage of them do not seek medical care. These findings are of great importance and call for campaigns to educate the public on the danger of stroke signs and their adequate management. These programs should become a priority as the Saudi population is increasing and aging. Indeed, prevention strategies should be accelerated to avoid a larger burden of stroke in the Kingdom.

\section{References}

1. Mokdad AH, Jaber S, Aziz MI, AlBuhairan F, AIGhaithi A, et al. (2014) The state of health in the Arab world, 1990-2010: an analysis of the burden of diseases, injuries, and risk factors. Lancet 383: 309-320.

2. Lozano R, Naghavi M, Foreman K, Lim S, Shibuya K, et al. (2012) Global and regional mortality from 235 causes of death for 20 age groups in 1990 and 2010: a systematic analysis for the Global Burden of Disease Study 2010. Lancet 380: 2095-2128.

3. GBD 2010 Arrow Diagram.

4. Stroke Signs and Symptoms.

5. Healey JS, Connolly SJ (2003) Atrial fibrillation: hypertension as a causative agent, risk factor for complications, and potential therapeutic target. The American Journal of Cardiology 91: 9-14.

6. State Heart Disease and Stroke Prevention Program Addresses High Blood Pressure.

7. al-Rajeh S, Larbi EB, Bademosi O, Awada A, Yousef A, et al. (1998) Stroke register: experience from the eastern province of Saudi Arabia. Cerebrovasc Dis 8: 86-89.

8. Awada A, al Rajeh S (1999) The Saudi Stroke Data Bank. Analysis of the first 1000 cases. Acta Neurol Scand 100: 265-269.

9. al Rajeh S, Awada A, Niazi G, Larbi E (1993) Stroke in a Saudi Arabian National Guard community. Analysis of 500 consecutive cases from a population-based hospital. Stroke 24: 1635-1639.

10. Al-Hamdan N, Saeed A, Kutbi A, Choudhry AJ, Nooh R (2011) Characteristics, risk factors, and treatment practices of known adult hypertensive patients in saudi arabia. Int J Hypertens 2010: 168739.

11. Al-Nozha MM, Abdullah M, Arafah MR, Khalil MZ, Khan NB, et al. (2007) Hypertension in Saudi Arabia. Saudi Med J 28: 77-84.

12. Saeed AA, Al-Hamdan NA, Bahnassy AA, Abdalla AM, Abbas MA, et al. (2011) Prevalence, Awareness, Treatment, and Control of Hypertension among Saudi Adult Population: A National Survey. Int J Hypertens 2011: 174135.

13. El Bcheraoui C, Memish ZA, Tuffaha M, Daoud F, Robinson M, et al. (2014) Hypertension and its associated risk factors in the kingdom of saudi arabia, 2013: a national survey. Int J Hypertens 2014: 564679.

14. Wadley VG, McClure LA, Howard VJ, Unverzagt FW, Go RC, et al. (2007) Cognitive status, stroke symptom reports, and modifiable risk factors among individuals with no diagnosis of stroke or transient ischemic attack in the REasons for Geographic and Racial Differences in Stroke (REGARDS) Study. Stroke 38: 1143-1147.

15. Global Database on Body Mass Index-BMI classification. World Health Organization.

16. Craig CL, Marshall AL, Sjöström M, Bauman AE, Booth ML, et al. (2003) International physical activity questionnaire: 12 -country reliability and validity Med Sci Sports Exerc 35: 1381-1395.

17. National Heatlth and Nutrition Examination Survey (NHANES) (2009) Health Tech/Blood Pressure Procedures Manual. CDC. 
Citation: Bcheraoui TCEI, Basulaiman M, AlMazroa MA, Daoud F, Tuffaha M, et al. (2014) Reported Stroke Symptoms and their Associated Risk Factors in the Kingdom of Saudi Arabia, 2013. J Hypertens 3: 177. doi:10.4172/2167-1095.1000177

Page 6 of 6

18. Blackwell DL, Lucas JW, Clarke TC (2014) Summary health statistics for U.S adults: national health interview survey, 2012. Vital Health Stat $10: 1-161$

19. Roger VL, Go AS, Lloyd-Jones DM, Benjamin EJ, Berry JD, et al. (2012) Heart disease and stroke statistics--2012 update: a report from the American Heart Association. Circulation 125: e2-2e220.
20. Olives C, Myerson R, Mokdad AH, Murray CJ, Lim SS (2013) Prevalence, awareness, treatment, and control of hypertension in United States counties, 2001-2009. PLoS One 8: e60308.

21. Memish ZA, Stephens GM, Steffen R, Ahmed QA (2012) Emergence of medicine for mass gatherings: lessons from the Hajj. Lancet Infect Dis 12: 56-65. 